MISES: Revista Interdisciplinar de Filosofia, Direito e Economia

ISSN 2318-0811

Volume II, Número 2 (Edição 4) Julho-Dezembro 2014: 605-609

\title{
Hayek e o Prêmio Nobel ${ }^{*}$
}

\section{Murray N. Rothbard**}

Resumo: Nesse texto, pela ocasião do Prêmio Nobel de Economia concedido a Hayek, o autor resume as principais contribuições desse autor à teoria econômica, metodologia e filosofia política, notando a importância dessas idéias para a resistência ao inflacionismo, planejamento central e ativismo macroeconômico que marcaram o século XX.

Palavras-Chave: Hayek, Prêmio Nobel.

\section{Hayek and the Nobel Prize}

Abstract: In this text, for the occasion of the Nobel Prize in economics awarded to Hayek, the author summarizes the main contributions of this author to economic theory, methodology and political philosophy, noting the importance of his ideas to the resistance to inflationism, central planning and macroeconomic activism. They characterized the twentieth century.

Keywords: Hayek, Nobel Prize.

Classificação JEL: B31

\footnotetext{
* O presente artigo foi publicado originalmente como: ROTHBARD, Murray N. The Nobel Prize. The Libertarian Forum, Vol. 6, No. 10 (October 1974).

Traduzido do original em inglês para o português por Gabriel Moreira Beraldi.

** Murray N. Rothbard nasceu em 2 de março de 1926, no Bronx, em Nova York. Graduou-se em Matemática, em 1945, na Columbia University, por onde também recebeu, em 1956, o título de Doutor em Economia. Lecionou no Brooklyn Polytechnic Institute, de 1964 a 1986, e na escola de negócios da University of Nevada, em Las Vegas, de 1986 até 1995. Rothbard foi o fundador e principal teórico do anarcocapitalismo, um firme defensor do revisionismo histórico, e uma figura central no movimento libertário norte-americano do século XX. É autor de mais de vinte livros, dentre os quais se destacam o tratado de economia Man, Economy, and State e Governo e Mercado (Instituto Ludwig von Mises Brasil, 2012). Faleceu no dia 7 de janeiro de 1995 em Nova York, nos Estados Unidos.
} 
A concessão, em 1974, do Prêmio Nobel em Ciências Econômicas ao grandeeconomista austríaco do livre mercado Friedrich August von Hayek (1889-1992) surge como uma agradável surpresa para seus admiradores neste país e em todo o mundo. Isso porque, desde a morte de seu distinto mestre, Ludwig von Mises (1881-1973), Hayek foi, aos 75 anos de idade, considerado o mais eminente economista liberal e um dos mais importantes defensores de uma sociedade livre.

O Prêmio Nobel veio como uma surpresa por dois motivos. Não apenas porque todos os Prêmios Nobel anteriores em economia tenham ido para progressistas à esquerda e opositores do livre mercado, mas, também, porque eles foram uniformemente concedidos para economistas que têm transformado a disciplina em uma suposta "ciência" preenchida por um jargão matemático e "modelos" irrealistas que são então utilizados para criticar o sistema de livre empreendedorismo e tentar planejar a economia através de um governo central.

F. A. Hayek não é apenas o maior economista do livre mercado; ele também tem liderado ataques aos modelos matemáticos e às pretensões de planejamento dos supostos "cientistas", além de integrar a economia a uma filosofia social libertária mais ampla. Ambos os conceitos têm sido, até o momento, um anátema para a organização do Nobel.

Todos nós podemos especular sobre as motivações que levaram o comitê do Nobel prestar esse bem-vindo, embora atrasado, tributo a Friedrich August von Hayek. Talvez um dos motivos seja a evidente ruptura dos ortodoxos "macroeconomistas" keynesianos, o que leva até mesmo os economistas mais conservadores a, pelo menos, considerar teorias e soluções alternativas. No entanto, talvez uma outra razão tenha sido o desejo de conceder o Prêmio a um opositor do notório esquerdista e socialista Dr. Gunnar Myrdal (1898-1987); dessa forma, a concessão do Nobel a Hayek fora uma necessidade de promover uma política de "equilíbrio". Assim, concedendo prêmios a esses dois polos opostos, a Academia Real de Ciências da Suécia citou Hayek e Myrdal "por seu trabalho pioneiro na teoria da moeda e da flutuação econômica, e pela análise, também pioneira, da interdependência dos fenômenos econômicos, sociais e institucionais".

De qualquer maneira, independente das motivações do comitê do Nobel, nós só podemos saudar o merecido tributo às imponentes contribuições e realizações de Friedrich Hayek. A primeira monumental contribuição de Hayek à economia foi $o$ desenvolvimento da Teoria Austríaca do Ciclo Econômico (TACE), com base no esquema pioneiro de Mises. Surgida no final dos anos 1920, e levando em consideração que Mises e Hayek estavam entre os poucos economistas do mundo que previram a Depressão de 1929, dois grandes trabalhos de Hayek sobre o ciclo econômico foram publicados em inglês como Monetary Theory and the Trade Cycle [Teoria Monetária e Ciclo Econômico ${ }^{1}$ em 1933, e o mais técnico Prices and Production [Preços e Produção] ${ }^{2}$ em 1931.

Durante o início da década de 1930, quando Hayek deixou a Áustria para lecionar na London School of Economics (LSE), a TACE, dele e de Mises, começou a ser amplamente adotada na Inglaterra e até mesmo nos Estados Unidos devido a Grande Depressão; infelizmente, essa teoria foi colocada de lado no auge da revolução keynesiana de $1936^{3}$ sem sequer ser considerada e muito menos refutada pelo estatismo de John Maynard

\footnotetext{
${ }^{1}$ HAYEK, F. A. Monetary Theory and the Trade Cycle. Trad. N. Kaldor \& H. M. Croome. London: Jonathan Cape, 1933.

${ }^{2}$ HAYEK, F. A. Prices and Production. London: George Routledge \& Sons, 1931.
}

${ }^{3}$ KEYNES, John Maynard. The General Theory of Employment, Interest and Money. London: Palgrave Macmillan, 1936. [Em língua portuguesa a obra pode ser encontrada na seguinte edição brasileira: KEYNES, John Maynard. A Teoria Geral do Emprego, do Juro e da Moeda. Apres. Adroaldo Moura da Silva; Trad. Mário R. da Cruz \& Paulo de Almeida; Rev. tec. Cláudio Roberto Contador. São Paulo: Nova Cultural, 1996. (N. do T.)]. 
Keynes (1883-1946) e seus discípulos. Agora que o keynesianismo está desmoronando teórica e empiricamente, o mundo da economia deve estar seriamente preparado para considerar novamente a teoria austríaca, pela primeira vez em quarenta anos.

Resumidamente, a importância da TACE de Hayek se dá porque é colocado nos ombros do governo e do sistema bancário por ele controlado a culpa pelo ciclo de expansão e recessão e, pela primeira vez desde os economistas clássicos do século XIX, absolvendo completamente a economia de livre iniciativa. Quando o governo e seu banco central encorajam a expansão do crédito bancário, isso não apenas causa inflação nos preços, mas também provocam crescentes maus investimentos, especificamente em bens de capital e subprodução de bens de consumo.

Portanto, o boom inflacionário induzido pelo governo não só prejudica os consumidores, aumentando os preços e o custo de vida, mas também distorce a produção e cria investimentos inviáveis. O governo é então confrontado, repetidamente, com duas escolhas básicas: ou se freia a inflação de crédito monetário e bancário, o que necessariamente levará a uma recessão, que servirá para liquidar os maus investimentos e retornar a uma estrutura genuína de livre-mercado de investimento e produção - ou se continua inflando até que uma inflação galopante destrua totalmente a moeda e provoque o caos social e econômico.

A relevância da teoria de Hayek para os nossos dias deve ser notoriamente óbvia, pois mostra como qualquer indício de recessão faz com que o governo entre em pânico e ligue as torneiras inflacionárias mais uma vez. $\mathrm{O}$ ponto é que, dado qualquer boom inflacionário, uma recessão é dolorosa, mas necessária, no sentido de devolver a economia a um estado de equilíbrio.

A prescrição política que flui da teoria hayekiana é, evidentemente, diametralmente oposta ao keynesianismo: interrompa o boom inflacionário artificial e permita que a recessão prossiga o mais rápido possível com o seu trabalho de reajustamento. $\mathrm{O}$ adiamento e as tentativas do governo de interromper ou interferir no processo de recessão só intensifica a agonia e leva nossa atual turbulência a uma inflação futura combinada com um grande processo de depressão. A análise de Mises e Hayek não é apenas a única teoria convincente sobre o ciclo econômico; é a única resposta abrangente da parte do livre mercado para o pântano keynesiano de planejamento de governo que estamos sofrendo hoje.

Mas F. A. Hayek não parou com esta contribuição monumental à economia. Na década de 1940, ele ampliou sua abordagem a toda área da economia política. Em seu best-seller The Road to Serfdom [O Caminho da Servidão], originalmente lançado em 1944, ele desafiou o clima intelectual pró-socialista e pró-comunista da época, mostrando como o planejamento socialista levará inevitavelmente ao totalitarismo, além de apresentar exemplos da maneira como a socialdemocracia da República de Weimar pavimentou o caminho para Adolf Hitler (1889-1945). Hayek também apresentou como o "pior sempre chega ao topo" em uma sociedade estatista. Em sua brilhante série de ensaios Individualism and Economic Order [Individualismo e Ordem Econômica] ${ }^{5}$ de 1948, demonstrou de modo pioneiro como o socialismo não consegue racionalmente fazer cálculos, pois carece de um sistema de preços de livre mercado, especialmente porque este está unicamente preparado para transmitir as informações de cada indivíduo para todos os outros. Na falta de um genuíno sistema de preços, o socialismo é necessariamente não dispõe de tais informações cruciais.

Além disso, na mesma obra, Hayek brilhantemente dissecou o modelo ortodoxo

${ }^{4}$ HAYEK, F. A. The Road to Serfdom. Chicago: The University of Chicago Press, 1944. [A obra está disponível em língua portuguesa na seguinte edição: HAYEK, F. A. O Caminho da Servidão. Trad. Anna Maria Capovilla, José Ítalo Stelle e Liane de Morais Ribeiro. São Paulo: Instituto Ludwig von Mises Brasil, 6 ${ }^{\mathrm{a}}$ Ed., 2010. (N. do T.)].

${ }^{5}$ HAYEK, F. A. Individualism and Economic Order. Chicago: The University of Chicago Press, 1948. 
irreal da "competição perfeita", demonstrando que o mundo real da livre competição é muito superior a absurda demanda por "perfeição" por parte dos advogados e economistas antitruste. Como corolário, Hayek, neste trabalho, começou uma série devastadora de ataques ao modelo de "equilíbrio geral" dos economistas matemáticos, mostrando quão absurdo e irreal tal critério foi ao atacar a livre iniciativa.

Em 1952, Hayek publicou seu magnífico The Counter-Revolution of Science [A Contra Revolução da Ciência] ${ }^{6}$, que continua a ser o melhor ataque contra as pretensões daqueles que planejam controlar as nossas vidas em nome da "razão" e da "ciência". Dois anos depois, de maneira muito clara em Capitalism and the Historians [Capitalismo e os Historiadores] ${ }^{7}$, Hayek contribuiu e editou uma série de ensaios que mostravam conclusivamente que a Revolução Industrial na Inglaterra, estimulada por uma economia mais ou menos de livre mercado, muito mais melhorou do que piorou o padrão médio de vida dos consumidores e trabalhadores ingleses. Dessa forma, Hayek encabeçou a lista dos que quebraram um dos mitos mais difundidos pelos socialistas sobre a Revolução Industrial.

Finalmente, nas obras The Constitution of Liberty [Os Fundamentos da Liberdade]", de 1960, Studies in Philosophy, Politics, and Economics [Estudos em Filosofia, Política e Economia] ${ }^{9}$ de 1967 e Law, Legislation, and

${ }^{6}$ HAYEK, F. A. The Counter-Revolution of Science: Studies in the Abuse of Reason. Glencoe: The Free Press, 1952.

${ }^{7}$ HAYEK, F. A. (Ed.). Capitalism and the Historians. Chicago: The University of Chicago Press, 1954.

8 HAYEK, F. A. The Constitution of Liberty. Chicago: The University of Chicago Press, 1960. [Em língua portuguesa o livro foi publicado na seguinte edição brasileira: HAYEK, F. A. Os Fundamentos da Liberdade. Intr. Henry Maksoud; Trad. Anna Maria Capovilla e José Ítalo Stelle. Brasília / São Paulo: Editora Universidade de Brasília / Visão, 1983. (N. do T.)].

${ }^{9}$ HAYEK, F. A. Studies in Philosophy, Politics, and Economics. London: Routledge and Kegan Paul, 1967.
Liberty [Direito, Legislação e Liberdade] ${ }^{10}$, cujos volumes foram lançados em 1973, 1976 e 1979, Hayek, entre outras notáveis contribuições, defendeu o ideal esquecido do Estado de Direito, em oposição ao governo dos homens, e enfatizou o único valor do livre mercado e da sociedade livre na criação de uma "ordem espontânea" que somente pode emergir da liberdade. Como apenas uma de suas conquistas, seu grande artigo, "The NonSequitur of the Dependence Effect" refutou o livro The Affluent Society [A Sociedade Aflunte ${ }^{11}$ de John Kenneth Galbraith (19082006), ao apontar que nada há de errado nas pessoas aprenderem e absorverem valores e desejos de consumo uns dos outros. E em seu cintilante ensaio "The Intellectuals and Socialism" [Os Intelectuais e o Socialismo] ${ }^{12}$, de 1949, F. A. Hayek estabelece a estratégia adequada que os libertários devem seguir: a importância de ter a coragem de seguir os socialistas na consistência, ao recusar-se a render-se aos ditames de curto prazo do compromisso e da conveniência; só assim seremos capazes de reverter a derrotar a onda coletivista.

Nós poderíamos continuar com muitas outras contribuições. Mas muito já foi dito

\footnotetext{
${ }^{10}$ Vale notar que quando Rothbard escreveu o presente artigo só havia o primeiro volume. HAYEK, F. A. Law, Legislation and Liberty. Chicago: The University of Chicago Press, 1973 / 1976 / 1979. 3v. [A trilogia foi publicada em língua portuguesa na seguinte edição brasileira: HAYEK, F. A. Direito, Legislação e Liberdade: Uma Nova Formulação dos Princípios Liberais de Justiça e Economia Política. Apres. Henry Maksoud; Trad. Anna Maria Copovilla, José Ítalo Stelle, Manuel Paulo Ferreira e Maria Luiza X. de A. Borges. São Paulo: Visão, 1985. 3v. (N. do T.)].
}

${ }^{11}$ GALBRAITH, John Kenneth. The Affluent Society. Boston: Houghton Mifflin Company, 1958. [Em língua portuguesa a obra pode ser encontrada na seguinte edição brasileira: GALBRAITH, John Kenneth. A Sociedade Afluente. Trad. Carlos Afonso Malferrari. São Paulo: Pioneira, 1987. (N. do T.)].

12 HAYEK, F. A. The Intellectuals and Socialism. University of Chicago Law Review, Vol. 16, No. 3 (Spring 1949): 417-33. Reimpresso em 1967 na já citada coletânea Studies in Philosophy, Politics, and Economics. 
aqui para apontar o grande alcance, a erudição e a riqueza das contribuições de F. A. Hayek à economia e à filosofia política. Como seu grande mentor, Ludwig von Mises, Hayek persistiu com grande coragem em se opor ao socialismo e ao estatismo do nosso tempo. Mas ele não apenas firmou uma oposição inabalável às modas atuais do keynesianismo, da inflação e do socialismo; ele - com nobreza, cortesia e grande erudição - prosseguiu com suas pesquisas para nos fornecer os conceitos alternativos para uma economia e sociedade livres.

F. A. Hayek merece não apenas o Prêmio Nobel, mas todas as honras que podemos conferir-lhe. Mas o grande tributo que podemos prestar, a Hayek e a Mises, é dedicar-nos a reverter a onda estatista e seguir em frente rumo a uma sociedade de liberdade. cos 